\title{
UN INTENTO DE HACER CIENCIA PARA ENSENAR CIENCIAS
}

COMIN DEL RIO, P.

Profesor de Ciencias Naturales

del I.B. «Joan Alcover» Palma de Mallorca.

\section{SUMMARY}

A methodological didactic experience is presented on the unit "the soil as nexus between Geology and Biology" as an example of learning through discovering.

\section{INTRODUCCION}

Los proyectos de educación en ciencias y sus correspondientes curriculum llegan retrasados a España en varias décadas con respecto a los paises de nuestro entorno europeo y anglosajón. En los EE.UU. comienzan a salir en 1956 cuando los rusos lanzan el primer satélite artificial y la Nacional Science Foundation lanza el primer proyecto de renovación didáctica en ciencias. E] comienzo de la década de los 70 es una verdadera explosión de curricula de ciencias. Sigue el periodo 1977-82 de revisión y crítica de los mismos con el proyecto de sintesis de Harms (1977), para teminar en el momento actual con la búsqueda de soluciones para el año 2000 (Yager, 1982). El colectivo docente del Estado Español no ha reaccionado, en general, sino muy puntualmente, al letargo conseguido por la discriminación y la infravaloración por parte de los poderes públicos de su función en la sociedad.

Existen dos tendencias en la enseñanza de las ciencias de la naturaleza. Una es verbalista y dogmática, preocupada ante todo por transmitir el máximo de conocimientos, leyes, teorias, etc. que se dan como un cúmuio de información que hay que aceptar tai cual, sin importar la metodologia científica ni la realidad natural que envuelve al alumno. Las consecuencias, de esta línea tradicional y dominante en paises como el nuestro, son claras: "Aislamiento de la naturaleza y rechazo del trabajo manual por parte de la sociedad" (Terrades, 1979).

Otra linea educativa es la que aplica la enseñanza por descubrimiento para producir conocimientos en ciencias. Sigue el auténtico significado del método cientifico, de forma que el alumno aprende ciencias haciendo Ciencia. La presente experiencia quiere sumarse a esta corriente de renovación que, desde hace algunos años, ha hecho eclosión en nuestro país y sigue la lí- nea del aprendizaje por descubrimiento, como alternativa a la enseñanza por recepción pasiva (Gene y Gil, 1982).

\section{PRINCIPIOS EN LOS QUE SE BASA LA EXPERIENCIA}

La experiencia que comentamos en estas lineas ha $\mathrm{si-}$ do puesta en práctica durante el curso $1982-83$ por un grupo de profesores de Bachillerato de Palma de Mallorca. Un total de 333 alumnos de Primero de BUP la han realizado muy satisfactoriamente, como comen. taremos en las conclusiones finales, pero va dirigida también para alumnos de los últimos cursos de EGB y de Formación Profesional. Açaba de ser publicada por el I.C.E. de la Universidad de Palma de Mallorca (Comin, 1984a y 1984b).

Los principios metodológicos-didácticos que orientan la experiencia pueden concretarse a los siguientes:

1. La Ciencia es un todo integrado. Se pretende dar una visión unitaria de la naturaleza, presentando el sueto como un sistema material que evoluciona a lo largo del tiempo y del espacio en sus aspectos físico, quimico, geológico y bioecológico. Este principio teórico de la Ciencia integrada se halla bellamente recogido en la Ley de Educación en su artículo 22.2 y en las orienta. ciones oficiales del Ministerio de Educación y Ciencia, tanto a nivel de segunda etapa de EGB como de BUP y F.P. En esta experiencia intentamos hacer realidad este desideratum teórico.

2. La metodología activa del descubrimiento dirigido es el hilo conductor de la secuencia de situaciones y de actividades que se desarrollan a lo largo de la unidad. El alumno es el principal protagonista de su propio aprendizaje: emite hipótesis, planifica modelos expe- 
rimentales, discute en grupos de trabajo, saca sus propias conclusiones, etc. En una palabra, se intenta uuna enseñanza de las ciencias acorde con la propia metodologia cientifica" (Gil, 1983).

3. El profesor es el facilitador del aprendizaje. En la linea del principio anterior en el que el alumno es el primer protagonisia, la figura del profesor adquiere un nuevo significado y función. No quiere decir que su papel sea secundario, muy al contrario, sus posibilidades de creación y actividad aumentan. No es un mero transmisor de conocimientos sino que facilita y orienla el aprendizaje del alumno, ayudado por el Guión programatico y por la Guía didáctica, donde se le ofrecen material e ideas que tiene que seleccionar, concretar y aplicar al centro y al grupo que tiene ante sí.

4. La realidad ambiental es la principal fuente de aprendizaje. Las tesis de la educación ambiental se hallan recogidas de manera práctica en la experiencia. Por ejemplo, continuamente se aterriza en ta realidad cotidiana, se proponen cuestiones prácticas que con la información y experiencia previstas en la programación se pueden razonar de una manera sanciila pero convincente. Toda la experiencia gira alrededor de la realidad mallorquina y balear que es el marco donde la he. mos experimentado. De todas formas la adaptación a “ialquier otra realidad ambiental es fácil de conseguir.

5. En fin, hemos tratado desde la perspectiva del suelo contribuir a la educación del hombre en su totalidad. En olras palabras, hemos procurado a propósito del tema del suelo hacer Ciencia para enseñar ciencias.

\section{RESUMEN DEL GUION PROGRAMATICO DF. LA EXPERIENCIA}

Insistimos en que tanto el Guión programático del alumno como la Guia didactica del profesor han sido publicados por el I.C.E. de la Universidad de Palma. Ofrecemos en este apartado una visión panorámica de la secuencia de sesiones y de actividades que se suceden a lo largo de la programación. Como recuerda en repetidas ocasiones la Guia didáctica y acabamos de comentar en el principio 2, no se trata de un guión tigido e inflexible sino que el profesor es quien debe adaptarlo a las caracteristicas del centro y, sobre todo, de la clase que tiene delante.

\subsection{Planteamiento del problema y emisión de hipótesis}

Se planta el tema y se centra el interés del alumno con la historia que relata el texto IV de Biologia Nuffield: «Un suelo hecho en casa».

En la segunda sestón se abre un diálogo sobre "¿cómo trabaja el cientifico?», para pasar a la emisión de hipótesis respecto al problema concreto: ¿Qué materiales forman el suelo? y terminar invitando a los alumnos a planificar, en pequeños grupos de trabajo, modelos experimentales que sometan a prueba las hipótesis intuidas. La tercera sesión se dedica a terminar el trabajo de grupo, si el tiempo fue muy justo en la sesión segunda, y a discutir en el foro de la clase los modelos de experimentación ideados por cada grupo.

Estas tres o cuatro primeras sesiones tienen como objetivo estimular al alumno para que, con los conocimientos e información que posee, desarrolte su creatividad antes de proporcionarle nueva información sobre el tema en cuestión. Con esta táctica pedagógica se logra que el alumno sienta la satisfacción de su propio esfuerzo, pida más información y la aprecie, en cuanto que le permite avanzar en aspectos que no se le habian ocurrido. Normalmente en estas sesiones introductorias los alumnos captan y descubren las hipotesis objeto de la actividad experimental del apartado 3.2 tras el bloque informativo de ese mismo apartado y cuyas hipótesis de trabajo se hallan recogidas en el apartado 3.2.6.

\subsection{Génesis, evolución y componentes del suelo}

\section{Bloque informativo}

(En la Guja didáctica se indican distintas maneras de llevar a cabo o desartollar cada uno de los bloques de información de la unidad y en el Guión programático están desarrollados).

3.2.1. El suelo es el resultado de la alteración de la capa superficial de la corteza terrestre.

3.2.2. Suelo natural y suelo agricola.

3.2.3. Causas de la alteración de las rocas.

- fenómenos físicos

- fenómenos químicos

- agentes biológicos

3.3.4. Suelos autóctonos y suelos aloctonos.

3.2.5. Origen de los suelos en el ciclo geológico.

3.2.6. Principales materiales componentes del suelo.

- el suelo contiene aire

- en el suelo hay agua

- el suelo contiene sustancias organicas en descomposición

- en el suelo hay sales minerales

- el suelo está formado por particulas o granos de diferentes tamaños.

\section{Actividad experimental}

Durante dos sesiones o más se contrastan las hipótesis del apartado 3.2.6. realizando los experimentos ideados por los alumnos en las primeras sesiones. El Guión programático del alumno ofrece ideas y ejemplos concretos sin tratar de agotarlos. Como apunta la Guía didáctica los alumnos «han de comparar los modelos que ellos elaboran con los que el guion les ofrece y hacer una sintesis que supere la simple cupias (Comin, 19846).

\section{Lectura complementaria}

Dedica la programación una clase o sesión a una lectura informativa complementaria acerca del origen de los suelos en relación con el ciclo geológico y la colonización progresiva biológica. El enfoque que insinúa la Gufa didáctica puede ser interesante cara la práctica 
de una metodologia de estudio por parte del alumno.

\section{Evaluación de objetivos operativos}

A estas alturas del desarrollo de la unidad se puede emplear una clase, o parte de ella, para una primera evaluación de objetivos.

\subsection{Textura, perfil y tipos de suelo}

\section{Bloque informativo}

(Se preven dos sesiones para la asimilación y discusión).

3.3.1. Textura o granulometria

3.3.2. Estructura del suelo

3.3.3. El perfil

- suelo propiamente dicho: horizontes A y B

- subsuelo u horizonte $C$

- el sustrato rocoso

3.3.4. Clasificación de los suelos

- criterio físico o de textura

- criterio químico o de composición

- criterio climático

- criterio genético evolutivo

\section{Actividad experimental}

Propone el guión una actividad opcional sobre una se. rie de hipótesis como las que siguen:

- «La capacidad de tomar y de retener el calor varía con la clase de suelon.

- «La exposición u orientación de la vertiente influye en la cantidad de calor que llega al suelo.»

- "La pendiente del suelo influye en la cantidad de calor que recibe."

- La temperatura del suelo influye en la germinación de las semilias y en el desarrollo de las plantas jóvenes."

- La temperatura del suelo influye en la vida animal que en él habita.»

\subsection{Intervención en la dinámica del sistema suelo}

\section{Bloque de información}

3.4.1. La destrucción del suelo

3.4.2. ¿Cómo proteger el suelo?

3.4.3. ¿Cómo mejorar el suelo?

3.4.4. ¿Como evitar el empobrecimiento del suelo?

3.4.5. El suelo como ecosistema

3.4.6. El suelo de las islas Baleares

- características y aproximación a los suelos de Mallorca

- utilización del suelo agricola de Baleares

- problemas y alternativas del campo balear.

\section{Actividad experimental de campo}

Se propone una salida didáctica a la naturaleza y se ofrece un esbozo de programación con orientaciones muy generales. Ya decimos en la Guia didáctica que "ces al profesor a quien corresponde elegir el itinerario concreto y hacer la programación de acuerdo con la localización y las posibilidades que da de sí el centro, el número de alumnos, etc.). (Comin, 1984b).

\section{Evaluación final de objetivos operativos}

Ofrece la Guia didáctica varias preguntas y cuestiones relativas a cada uno de los objetivos fijados al principio de la programación.

\section{CONCLUSIONES}

Una conclusión se deduce de esta experiencia es que caminar hacia una renovación profunda en la meto. dologia y en la didáctica de las ciencias en nuestro pais es posible con el esfuerzo del profesorado, estimulado y alentado por la administración. Sin embargo, las estructuras y los medios actuales con los que cuentan nuestros centros no favorecen una docencia en la linea de esta experiencia, al contrario, no permiten aplicarla sin problemas a todo el programa oficial propuesto para un curso. Por tanto, de acuerdo con nuestra ex. periencia, se impone «aliviar los temarios, de forma lógica y razonada, de la pesada carga teórico. dogmática» (Ochaita, 1980), de que adolecen. De igual modo creemos que hay que pensar en reducir el número de alumnos/profesor, asi como descongestionar y flexibilizar el horario escolar.

Los resultados obtenidos respecto a los principios metodológicos propuestos en la experiencia, no han podido ser más satisfactorios, a pesar de la pobreza de medios con que hemos contado el grupo de profesores que hemos experimentado. Tal es la conclusión global a la que se llega de la encuesta realizada con los alumnos de Primero de BUP que la realizaron. A la pre. gunta ${ }_{¿} Q$ Qué actividades o aspectos de la experiencia te gustaron más? Procura dar razones," la respuesta más repetida hace referencia al método activo de des. cubrimiento seguido: ... «trabajar con hipótesis»... «La comprobación de hipótesis con experimentos» ... "La forma de aprender entendiendo el porqué»... "La experiencia o actividades prácticas de laboratorio"... Hay un segundo grupo de respuestas que indican hasta qué punto los alumnos se sintieron protagonistas de su propio aprendizaje: «... nuestra participación»... “Trabajar en grupo»... «Aprendimos divirtiéndonos»... "Este modo de estudio dio lugar a discusiones y diálo. gos entre alumnos y profesores» ... "porque en ello te. niamos un papel importante" ... etc.

Entre las criticas, la más repetida, y casi única, es la que apunta a la falta de tiempo consecutivo para realizar las experiencias: «... tener poco tiempo para comprobar las hipótesis»... «la hora de laboratorio es muy corta»... «Para el laboratorio tendríamos que tenet más tiempo»... etc. Y es que el grupo de profesores que aplicamos la experiencia no contamos en ese cur. so con dos horas seguidas en el horario semanal. He aquí otro de los minimos necesarios para seguir esta linea metodológica.

Un comentrio más amplio a los resultados de la encuenta a 333 alumnos de Primero de BUP se halla en la "Guía didáctica del Profesor» (Comin, 1984b). 
No podemos terminar sin indicar que el alto grado de aceptación y participación de nuestros alumnos en la experiencia, puesto en evidencia en esta encuesta, in- dican que la línea metodológica de la misma sintoniza con lo que el alumnado espera de sus maestros en esta hora de cambio y de renovación.

\section{REFERENCLAS BIBLIOGRAFICAS}

COMIN, P., 1984a, El sòl, pont entre la Geología y la Bio. logía. Gujó programatic de l'alumne. I.C.E. Universitat de Palma de Mallorca.

COMIN, P., 1984b, El suelo, puente entre la Geologia y la Biologia. Guia didáctica del profesor. I.C.E. Universidad de Paima de Mallorca.

GENE, A. y GIL, D., 1982, Enseñanza de las ciencias naturales por descubrimiento. Cuad. de Pedag., 94, 64-66

GIL, D., 1983, Tres paradigmas básicos en la enseñanza de las ciencias. Ensehanza de las ciencias, 1, 26-33.

HARMS, N.C., 1977, Project synthesis: an interpretative con- solidation of research identifying needs in natural science education. (A proposal to the National Science Foundation) Boulder, Colo, University of Colorado.

NUFFIELD BIOLOGIA, 1972, Curso de 5 textos para el alumno y sus correspondientes guias para el profesor. Ed. Omega, Barcelona.

OCHAITA, L., 1980, Reflexiones históricas sobre la didáctica de las ciencias. Rev. de Bachillerato, 16, 2-6

TERRADAS, J. 1979, Ecologia y educación ambiental. Cuadernos de Biologia, ed. Omega, Barcelona.

YAGER, R.E., 1982, The crisis in Biology Education. The american Biology teacher, 44 (6), 328-336. 